\title{
The Psychosocial and Financial Ramifications of Thalassemia on Parents of Thalassemic Children Presented at Tertiary Care Hospitals
}

\author{
Nimra Shafi*, Shakeel Ahmed, Abdul Raheem Siddique \\ Medical and Dental College, Bahria University, Karachi, Pakistan \\ Email: *shafinimra809@yahoo.com
}

How to cite this paper: Shafi, N., Ahmed, S. and Siddique, A.R. (2021) The Psychosocial and Financial Ramifications of Thalassemia on Parents of Thalassemic Children Presented at Tertiary Care Hospitals. Open Journal of Pediatrics, 11, 379-387. https://doi.org/10.4236/ojped.2021.113034

Received: June 15, 2021

Accepted: July 27, 2021

Published: July 30, 2021

Copyright $\odot 2021$ by author(s) and Scientific Research Publishing Inc. This work is licensed under the Creative Commons Attribution International License (CC BY 4.0).

http://creativecommons.org/licenses/by/4.0/

\begin{abstract}
Thalassemia major is a disease that requires frequent admission of patients to medical facilities along with unremitting medicinal and blood transfusion aids. The families of such patients suffer in different aspects of their lives. The severity of the challenges they are subject to has been examined in this research with reference to Karachi and Hyderabad. Chief focus is rendered to the assessment of psychological, social, and economical implications. Objective: The aim of this study is to assess the social, financial and psychological impact of thalassemia on parents of children suffering from thalassemia. Study Design: Cross-sectional study. Place and Duration of Study: The study was conducted at PNS Shifa Hospital Karachi, Jinnah Post Graduate Medical Institute Karachi, and Civil Hospital Hyderabad. Methodology: A cross-sectional study which was aimed at establishing the social, financial and psychological impact of thalassemia on families of affected children was conducted at PNS Shifa Hospital, Jinnah Post Graduate Medical Institute Karachi, and Civil Hospital Hyderabad. The data was collected using a structured questionnaire as tool for data collection. The questionnaires were filled by interviewing the parents of registered thalassemia major patients by the researchers. Data was analyzed and interpreted using the SPSS 25.0 version. Results: The total number of participants which were meeting the inclusion criteria was 237. Study population with high income (above PK rupees $35,000)$ is demonstrated to be less severely affected than the low earning study group. $17 \%$ of the parents in the study admitted to having negative impact of their child's illness on their relationship while $40 \%$ of study participants reveal their child is ignored/marginalized by relatives. About $80 \%$ of participants acknowledged feeling sad and depressed sometimes but only $25 \%$ of them take antidepressant medication.
\end{abstract}




\section{Keywords}

Thalassemia Major, Social, Financial Impact

\section{Introduction}

Estimated 7\% of world population is carrier of hemoglobin disorders [1] and approximately $1.5 \%$ of world population carries gene for beta Thalassemia [2]. Each year, 50,000 to 100,000 children die of thalassemia major in low and middle income countries [1]. Worldwide incidence level is estimated as 1 in every 100,000 [3]. Unfortunately, in Pakistan the number of children affected with transfusion dependent thalassemia is relatively higher than in most countries [4]. This is attributed to factors such as high frequency of gene, consanguineous marriages, high birth rate and rapidly increasing population [5]. Presence of thalassemia has been observed in all parts of the country [4]. Every year, 5000 children are born with thalassemia major in Pakistan, which puts the estimate of affected children in 5 out of 100, with the carrier rate being 5\% [6] [7]. Furthermore, it was found in a study that children affected with refractory anemia had $83 \%$ chances to be detected with beta thalassemia [8]. A wide phenotypic spectrum of thalassemia has been observed and $\beta$-thalassemia major is a severe transfusion-dependent form of the disease, associated with various different complications that are caused by tissue hypoxia and also because of iron overload. Repeated transfusions and increased intestinal iron absorption are the two main sources of iron overload [9].

In developing countries lack of competence in dealing effectively with the disease arises due to a number of factors [10]. B-thalassemia is renowned as the most commonly occurring disorder in the inherited hematological and single gene disorders family [11] [12]. In this disorder, a reduced production of hemoglobin is observed causing a severe case of anemia among patients [13]. Hemoglobin molecule is primarily composed of two of each alpha and beta chains, characterized by their formation [3] [13]. Due to a defect in messenger RNA, the beta chain acquires an erroneous synthesis causing a deformation of RBCs [14]. The occurrence of severe anemia requires the patients to be transfused with blood at regular intervals along with iron chelation therapy and sometimes bone marrow transplantation [15] [16]. However, the compliance with treatment poses several challenges to the families of the affected individuals [17].

In thalassemia, patient serum ferritin detects total body iron, if the level of ferritin is above $2500 \mathrm{mg} / \mathrm{d}$, in 15 years, this leads to multiple complications such as cardiac disease. Parents of thalassemic children are also concerned about many other problems such as bony deformity, appearance of the child, poor self-image, short stature delayed sexual development, and frequent hospital visits. Hemosiderosis is a major cause of mortality in these patients [1] [18]. Such patients also develop complication like cardiovascular diseases infections, bone 
defects and diabetes [19]. Thalassemic patients can only be cured by bone marrow transplant but unfortunately is beyond the reach of majority of the families in Pakistan [20].

In high-income countries, to prevent the disease related complications and improve outcomes for thalassemia patients variable measures are implemented such as the provision of safe blood transfusions, oral and parenteral iron chelating agents, noninvasive and regular iron monitoring, plus many other methods of supportive care [21] [22].

These challenges are examined separately in this study with the context of psychological, financial and social aspects.

\section{Methodology}

This cross-sectional study was carried out at PNS Shifa Hospital Karachi, Jinnah Post Graduate Institute Karachi, and Civil Hospital Hyderabad. Data was collected based on a structured questionnaire. Parents of children suffering from transfusion dependent thalassemia major were included in the study. Data collection spanned over a period of 6 months, from June 2018 to December 2018. The sample size was determined to be 237 , as calculated by standard formula. The Parents were interviewed using a preset questionnaire by the researcher after acquisition of verbal consent from each participant and explaining the aims and objectives of the study.

Questions concerning the educational status of parents, monthly income, expenses on travelling to hospital, transfusions, chelating medicines, social life of parents and how their child's terminal illness affects their relationship and mental health were included. Data collected was analyzed through software SPSS version 25. This study has been approved by ethical review committee of Bahria University Medical and Dental College. Reference No: ERC 57/2018.

\section{Sample Size}

Sample size was calculated from online software openepi.com version 3. The statistical parameters were $95 \%$ confidence $5 \%$ margin of error. Population size for finite population correction factor $\mathrm{N}=100,000$ and prevalence of beta thalassemia was $5 \%$ (reference study). The required sample size was 237 .

Formula used was,

$$
\text { Sample sizen }=[\operatorname{DEFF} * N p(1-p)] /\left[\left(d^{2} / Z^{2}{ }_{1-\alpha / 2} *(N-1)\right)+p *(1-p)\right]
$$

\section{Results}

Results obtained from the data are analyzed from the tabulated frequencies attained through utilization of SPSS 25 incorporating frequency analysis, crosstab analysis and chi square tests.

\subsection{Financial Ramifications}

Participants of the study classified according to their monthly income are ag- 
gregated into Figure 1.

Figure 2 demonstrates the frequency attained comprehensively with financial ramification and their light, moderate and severe impacts upon participants $(\mathrm{n}=$ 237).

Frequent admission to the hospital affected $25 \%(\mathrm{n}=60)$ populations lightly, with $54 \%(n=129)$ having moderate and $20 \%(n=48)$ having severe repercussions on the financial stability. Crosstab analysis represented higher income group as being affected less severely (12\%) and lowest income affected more severely $(28 \%)$. Chi square test analysis represented the $\mathrm{p}$ value to be 0.007 , indicating a relation among the two variables. Cross analysis of purchasing blood and monthly income demonstrated slight effect on income group above-35,000 with $8 \%$ admitting severe effects. In contrast, lowest income group participants were affected severely with $26 \%$ result acquisition. Similar patterns were observed in bivariate analysis of travelling to hospital and purchasing medicine with monthly income with chi square tests representing the $\mathrm{p}$ value to be 0.003 and 000 respectively as attained from SPSS 25.

\subsection{Social Ramifications}

In Table 1, frequencies evaluated from the responses generated from the data are tabulated against each variable. In response of how conditions of their lives were affected due to having a thalassemia major patient in the family, $31.2 \%$ ( $\mathrm{n}=$

\section{Monthly Income Frequency}

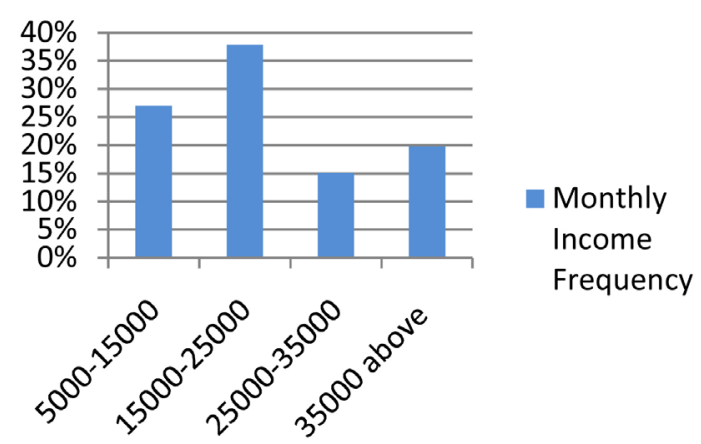

Figure 1. Monthly income frequency of participants.

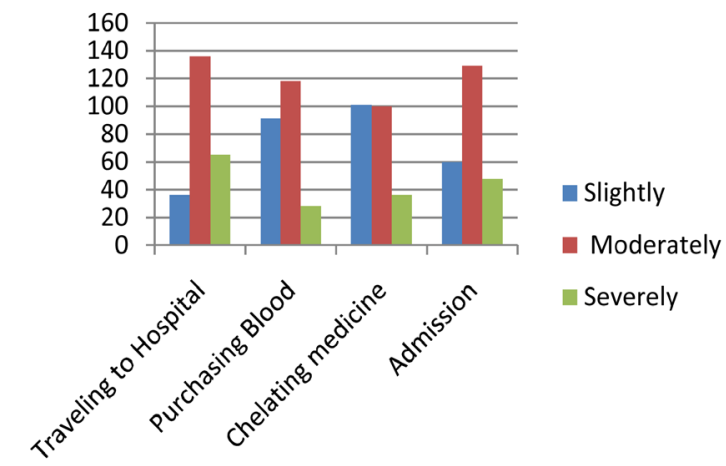

Figure 2. Aggregates of financial ramifications. 
Table 1. Social ramifications variables analysis.

\begin{tabular}{lcc}
\hline \multicolumn{1}{c}{ Variable } & $(\mathrm{n})$ & Percentage (\%) \\
\hline Affected relation with spouse & 41 & $17.30 \%$ \\
Yes & 196 & $82.70 \%$ \\
No & & \\
Child stigmatized by relatives & 95 & $40.1 \%$ \\
Yes & 142 & $59.9 \%$ \\
No & & \\
Lesser attention to other children & 47 & $19.8 \%$ \\
Yes & 88 & $37.1 \%$ \\
No & 102 & $43 \%$ \\
May be & & \\
Education of father & 45 & $19 \%$ \\
Illiterate & 80 & $33.8 \%$ \\
Matric & 57 & $24.1 \%$ \\
Intermediate & 55 & $23.2 \%$ \\
Graduate & & \\
Education of mother & 111 & $46.8 \%$ \\
Illiterate & 75 & $31.6 \%$ \\
Matric & 37 & $15.6 \%$ \\
Intermediate & 14 & $5.9 \%$ \\
Graduate & &
\end{tabular}

Table 2. Psychological ramifications of variables analysis.

\begin{tabular}{lcc}
\hline \multicolumn{1}{c}{ Variable } & (n) & Percentage $\%$ \\
\hline Feel depressed or sad & 190 & 80.2 \\
Yes & 47 & 19.8 \\
No & & \\
How often do you feel depressed & 64 & $33.7 \%$ \\
Everyday & 87 & $45.8 \%$ \\
Once a week & 39 & $20.5 \%$ \\
Once in a month & & \\
Take medicine for depression & 58 & $24.5 \%$ \\
Yes & 179 & $75.5 \%$ \\
No & & \\
Feel intolerant of things & 21 & $8.9 \%$ \\
Not at all & 160 & $67.5 \%$ \\
Sometimes & 56 & $23.6 \%$ \\
Most of the time & & \\
Unable to get enjoyment & 19 & $8 \%$ \\
Not at all & 137 & $57.8 \%$ \\
Sometimes & 81 & $34.2 \%$ \\
Most of the times & & \\
Scared thinking grief of child & 80 & $3.4 \%$ \\
Not at all & & \\
Sometimes & & \\
Most of the times & & \\
\hline
\end{tabular}


74) of the participants agreed to have acquired financial constraints along with finding it challenging to manage routine activities effectively.

\subsection{Psychological Ramifications}

Table 2 shows that $80 \%$ of the participants acknowledged feeling depressed or sad, with $78 \%$ agreeing for recurrence every day or once a week. Upon being asked if they took any medicine for coping with depression $75 \%$ responded negatively. $67 \%$ of participants identified exhibiting intolerance some of the times with $92 \%$ recognizing they were unable to attain any form of enjoyment in their lives some or most of the times. 96\% $(n=229)$ of the interviewees acknowledged that they were scared about thinking of the grief of their affected child. $92 \%$ ( $n=$ 218) of the participants conceded to have felt desolated or hopeless about the future some or most of the time.

\section{Discussion}

Thalassemia major is a chronic, lifelong illness, requiring scheduled blood transfusion, regular medicines and repeated hospital visits, which place patients and their families under great psychological and financial burden. The primary purpose of this study was to evaluate the impact on families of thalassemia major patients in three distinctive areas. The data generated from the questionnaire and evaluated in the results has equipped us with the ability to form a few inferences. Financially, it was observed that lower income class families, mostly from the PK Rupees 5000 - 15,000 monthly income group, were affected the most in contrast to the higher income groups. $83 \%$ admitted to having financial constraints with $74 \%$ severely affected by purchasing blood, medicines, traveling to hospital and admissions. A study conducted in Multan produced similar results [23]. A study conducted in Srilanka showed 30\% of families had severe economic problems [24]. Irrespective of the income classes, the responses centered majorly on moderate scale (Figure 2). However, through chi square tests, the $\mathrm{p}$ value obtained enabled us to deduce the inferences in significance of the income classes. Furthermore, among social implications it was observed that the ratio of illiteracy in mothers of the affected patients was higher in comparison with fathers. 17.3\% respondents had confessed to have troubled relationship with their spouse as a consequence of dealing with the child's illness, while it was $23 \%$ in another study [25]. 39\% participants revealed lack of support from relatives. $62 \%$ participants had difficulty managing routine activities, similar to another research that was conducted [25]. This study revealed that $19.8 \%$ feel they give lesser attention to other children because of their child disease. $80 \%$ participants reported to feel depressed or sad, $24 \%$ take medication for depression. In a study conducted in Multan 29\% parents had moderate to severe depression while 3\% had severe depression [20]. The study shows that $92 \%$ participants felt there is nothing in the future to be hopeful regarding their child's terminal illness. Through this analysis it can be concluded that psychological implications on the 
families of thalassemia major patients are significant.

\section{Conclusion}

Through the findings of this research it was established that lower income classes had a higher chance of suffering economically due to presence of a child suffering from thalassemia major. Adverse consequences of the disease on mental health of the families of affected children were also deduced.

\section{Author Contributions}

Conception and design: Nimra Shafi, Shakeel Ahmed;

Collection of data: Nimra Shafi, Abdul Raheem;

Analysis and interpretation of data: Nimra Shafi, Shakeel Ahmed;

Statistical analysis: Faisal Fahim;

Drafting of article: Nimra Shafi;

Critical review of article: Shakeel Ahmed.

\section{Acknowledgements}

We gratefully thank Faisal Fahim for statistical assistance.

\section{Conflicts of Interest}

The authors declare that there is no conflict of interest.

\section{References}

[1] Oliveiri, N.F. and Brittengham, G.M. (1997) Iron-Chelating Therapy and the Treatment of Thalassemia. Blood, 89, 739-761. https://doi.org/10.1182/blood.V89.3.739

[2] Cao, A., Conqui, R., Sallanio, M.C., et al. (2008) Thalassemia and Glucose 6 Phosphate Dehydrogenase Screening in 13 to 14 Year Old Students of the Sardinian Population: Preliminary Findings. Community Genetics, 11, 121-128. https://doi.org/10.1159/000113873

[3] Galanello, R. and Origa, R. (2010) Beta-Thalassemia. Orphanet Journal of Rare Diseases, 5, Article No. 11. https://doi.org/10.1186/1750-1172-5-11

[4] Lodhi (2003) Economics of Thalassemia Management in Pakistan. In: Rawalpindi, A.S., Ed., Thalassemia Awareness Week, Friends of Thalassemia, Rawalpindi, 9.

[5] Alwan, A. and Model, B. (1997) Community Control of Genetic and Congenital Disorders. WHO Regional Office for the Eastern Mediterranean, Alexandria, 24. https://apps.who.int/iris/handle/10665/119571

[6] Azam, F. (2009) 100,000 Pakistanis Suffering from Thalassemia. The Nation, May 8. https://nation.com.pk/08-May-2009/100000-pakistanis-suffering-from-thalassemia

[7] Khatak, M.F. and Saleem, M. (1992) Prevalence of Heterozygous Beta Thalassemia Northern Areas of Pakistan. Journal of Pakistan Medical Association, 42, 32-34.

[8] Saleem, M., Ahmed, P.A., Mubarik, A. and Ahmad, S.A. (1985) Distribution Pattern of Hemoglobinopathies in Northern Areas of Pakistan. Journal of Pakistan Medical Association, 35, 106-109.

[9] Taher, A.T., Weatherall, D.J. and Cappellini, M.D. (2018) Thalassaemia. The Lan- 
cet, 391, 155-167. https://doi.org/10.1016/S0140-6736(17)31822-6

[10] Weatherall, D.J. (2005) The Challenge of Thalassemia for the Developing Countries. Annals of the New York Academy of Sciences, 1054, 11-17. https://doi.org/10.1196/annals.1345.002

[11] WHO (2012) Genomic Resource Center. Genes and Human Diseases. https://www.who.int/search?page $=1$ \&pagesize $=10 \&$ query $=$ genetic $\% 20$ diseases $\&$ $\underline{\text { sort }=\text { relevance } \& \text { sortdir }=\text { desc } \& \text { default }=\text { AND \&f.Countries.size }=100 \& f \text {.Lang.filter }}$

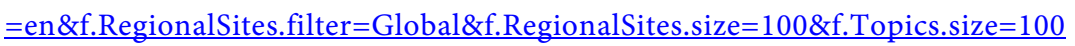
\&f.contenttype.size $=100 \&$ f.doctype. . $i z e=101 \&$ facet.field $=$ RegionalSites $\&$ facet.fi eld=Topics\&facet.field $=$ doctype $\&$ facet.field $=$ Countries\&facet.field $=$ contenttype \&facet.field $=$ Lang\&tune $=$ true \&tune $.0=3 \&$ tune $.1=2 \&$ tune $.2=2 \&$ tune $.3=3 \&$ tune .4 $=180$ \&tune. $5=75$

[12] Warrel, D.A., Cox, T.M. and Firth, J.D. (2010) Oxford Textbook of Medicine. Fifth Edition, Volume 3, Oxford University Press, Oxford, 4424-4426.

https://doi.org/10.1093/med/9780199204854.001.1

[13] Vehapoglu, A., Ozgurhan, G., Demir, A.G., Uzuner, S., Nursoy, M.A., Turkmen, S., et al. (2014) Hematological Indices for Differential Diagnosis of Beta Thalassemia Trait and Iron Deficiency Anemia. Hindawi Publishing Corporation, London. https://doi.org/10.1155/2014/576738

[14] Benz, E.J. and Forget, B.G. (1971) Defect in Messenger RNA for Human Hemoglobin Synthesis in Thalassemia. The Journal of Clinical Investigation, 50, 2755-2760. https://doi.org/10.1172/JCI106778

[15] Shanmugam, V. and Ramchandra (2015) Stress Factors among Caregivers of Children with Thalassemia. Manipal Journal of Nursing and Health Sciences, 1, 39-42.

[16] Schrier, S.L. (2002) Pathophysiology of Thalassemia. Current Opinion in Hematology, 9, 123-126. https://doi.org/10.1097/00062752-200203000-00007

[17] Caro, J.J., Ward, A., Green, T.C., Huybrechts, K., Arana, A., Wait, S., et al. (2002) Impact of Thalassemia Major on Patients and Their Families. Acta Haematologica, 107, 150-157. https://doi.org/10.1159/000057633

[18] Brittenham, G.M., Nathan, D.G., Olivier, N.F., Pioppard, M.J. and Weather, D.I. (2003) Deferiprone versus Deferoxamine in Thalassemia, and $\mathrm{T} 2 *$ Validation and Utility. The Lancet, 361, 183-184. https://doi.org/10.1016/S0140-6736(03)12223-4

[19] Ali, S., Sabih, F., Jehan, S., Anwar, M. and Javed, S. (2012) Psychological Distress and Coping Strategies among Parents of Beta-Thalassemia Major Patients. International Conference on Clean and Green Energy IPCBEE, Vol. 27, 124-128.

[20] Ishfaq, K., Naeem, S., Ahmad, T. and Zainab, S. (2016) Psychosocial and Economic Impact of Thalassemia Major on Patient's Families. Isra Medical Journal, 8, 24-27.

[21] Amid, A., Saliba, A.N., Taher, A.T. and Klaassen, R.J. (2015) Thalassaemia in Children: From Quality of Care to Quality of Life. Archives of Disease in Childhood, 100, 1051-1057. https://doi.org/10.1136/archdischild-2014-308112

[22] Rund, D. (2016) Thalassemia 2016: Modern Medicine Battles an Ancient Disease. American Journal of Hematology, 91, 15-21. https://doi.org/10.1002/ajh.24231

[23] Ishfaq, K., Shabbir, M., Naeem, S. and Hussain, S. (2015) Impact of Thalassemia Major on Patients and Families in South Punjab Pakistan. The Professional Medical Journal, 22, 582-589.

[24] Dayasiri, K.C., Kulathilake, A. and Mudiyanse, R.M. (2018) Clinical Profiles, Medical Complications and Quality of Life of Children Diagnosed with Thalassaemia Major in Peradeniya Teaching Hospital. Sri Lanka Journal of Child Health, 47, 
112-117. https://doi.org/10.4038/sljch.v47i2.8475

[25] Aziz, et al. (2012) Psychosocial Problems of Pakistani Parents of Thalassemic Children: A Cross Sectional Study Done in Bahawalpur, Pakistan. BioPsychoSocial Medicine, 6, 15. https://doi.org/10.1186/1751-0759-6-15 